\title{
Multimedia Analysis and Design: a Conceptual Framework
}

Vito Roberto $^{1}$, Elio Toppano ${ }^{2}$

\begin{abstract}
The paper proposes a conceptual model inspired to semiotic theories, to be applied to the analysis and design of multimedia. We introduce a meta-model with four levels of semantic aggregation. There results a framework of concepts, relations and processes accounting for the multiple meanings that arise from a multimedia text. We explore the effectiveness of the model by considering four commercial clips by the brand Lancôme. Our analysis confirms that the framework is well suited to the analysis, indexing, design of narrative multimedia.
\end{abstract}

Keywords Multimedia ' Analysis ' Semiotic ' Design ' Commercials · Advertisements

\section{Introduction and related work}

Conceptual models of multimedia play a foundamental role for analysis, annotation, indexing, design. The richer is the model in terms of entities, properties and relations, the more effective it is. We briefly account for a number of models proposed in the literature by classifying them according to the basic approach they follow.

The multimedia as a system of media assets. The focus is on the media as "data containers" - i.e., written texts, images, sound objects, audio-visuals, etc. combined in space and time to achieve some intended goals. Technological features and modes of interaction are the main concerns. Relevant issues are, e.g., coding and compression algorithms, synchronization solutions, the spatial layout, etc. An active interaction occurs in products like hypermedia and games. Such a classical perspective is embodied in several conceptual models [31]. In spite of minor differences, the underlying model is organized in five issues: content; logical and temporal structure; presentation; interaction; technical infrastructure. Accordingly, the design process is decomposed into: the content; its logical structure; layout and style; interaction; implementation. A weakness of this

\footnotetext{
${ }^{1}$ Dipartim. Scienze Matematiche, Informatiche e Fisiche (DMIF), Università di Udine, Italy Tel.: +39-0432-558439 Fax:+39-0432-558499 E-mail: vito.roberto@uniud.it

${ }^{2}$ Dipartim. Scienze Matematiche, Informatiche e Fisiche (DMIF), Università di Udine, Italy

Tel.: +39-0432-558431 Fax: +39-0432-558499 E-mail: elio.toppano@uniud.it
} 
perspective, as pointed out by [51], is the lack of "cement" connecting the quoted elements that are related in non-trivial ways.

The multimedia as a system of signs. The focus moves from data to languages, regarded as systems of signs. Classical Semiotics [11] defines a sign as an entity composed by the signifier (expression) and a signified (content), linked by a signification relationship. Viewing multimedia in terms of signs has opened novel perspectives to analysis, interpretation and design. Not only media assets, but narrative patterns and discourses are aggregates of signs. As a consequence, meanings are also conveyed by composition, presentation and style choices. Pioneering semiotic approaches concern the design of user interfaces [32, 37-39]; multimedia content analysis and retrieval $[9,4]$; evaluation methods [34, 5, 23].

The multimedia as a text. A coherent system of related sign structures is a "text". Two research directions are noteworthy. First, narrative theories study how stories can be expressed in multimedia texts such as videos and animations. Narrative models date back to the 90s [10]; more recently ref. [40] illustrates a multilayered conceptualization of digital videos with three levels: layout, content, semantic index. For each level a core set of concepts is introduced. Ref. [27] proposes formal ontologies devoted to characters and story. The contributions [3] and [48] focus on the application of semiotics of film and social semiotics, respectively, to the analysis of audio-visual artefacts. The second research direction refers to Multimodal Discourse Analysis (MDA). MDA adopts a threefold model of the articulation of meanings: ideational, interpersonal and textual [33]. The model can be applied to written texts, still and moving images, as well as music $[20,50,6]$. A relevant issue concerns the semantic consistency of meanings across the modalities: e.g., is the ideational meaning of the visual track coherent with the same meaning of the music associated?

The multimedia as a bearer of experience. By experience we mean the "felt experience", i.e., the stream of thoughts, feelings, emotions and perceptions evoked by the multimedia during its use [52]. As a consequence, designing means prefiguring the experience one intends to evoke into the target users. By stating that the multimedia is a bearer of experience we do not mean that the artefact contains in some way an experience to be transferred to the user. Rather, the artefact establishes the conditions that make an intended experience more likely than others, given the target user, his/her interpretive habits and the context of use. Several experience-centered models have been proposed $[21,13,12]$.

The multimedia as a persuasive message. A main concern is the social and cultural impact of the artefact, i.e., how it may influence the attitudes, behaviours and worldviews of people and affect the quality of life [49]. In particular, a multimedia may be regarded as a bearer of ethical, political, cultural values that are intentionally inscribed in it as a set of symbolic meanings to be communicated, for 
example, by a narrative. Models have been proposed within Value-centered Design [8]; Value-sensitive Design [16]; Design for Well-being [12]; Persuasive Technologies [15]; Design for Socially Responsible Behavior [47]. Most of the multimedia products reported in the literature fall into the categories of marketing and brand communication; public information campaigns; education; health promotion; environmental protection.

The approaches introduced so far should not be viewed as alternative ones, but rather as results of the evolution of the basic model: the mere layout of media assets has been progressively enriched with semantic issues referring to meaning structures; experiences; ethical values and their social impact. Such an evolution occurred in a fragmentary way, so there is no unique model representing all of the topics, but rather a set of models addressing specific issues.

Practitioners seem to prefer flexible approaches that can be readily adapted to the project at hand [1], [35]. Thus, the suggestion is providing designers with frameworks (design toolkits) that do not strictly prescribe what to do, but support focusing on sense-making and relevance. Design thinking and critical skills are expected to support the multimedia products with quality and creativity [2].

With the motivations reported here above, we focus on the articulation of meanings of a multimedia text, and propose a structured framework inspired to the semiotic concepts by Greimas [18]. It can be viewed as a meta-model - an interpretive tool - for the analysis, design and comparison of products [41].

The paper is organized as follows: the main features of the framework are presented in the next Section, and detailed in the following ones 3, 4. Results of the analysis of advertisement clips are reported in Section 5. Section 6 contains our conclusions.

\section{A reference model}

\subsection{Basic scheme}

The scheme in Figure 1 accounts for the dynamics of communication among stakeholders. The actual sender - e.g., the designer, on behalf of a brand - and the actual receiver - the user - are connected by a medium like a desktop PC enabling the circulation of a multimedia text through the Net. The text includes the reflected images - the simulacra - of designer and user, called addresser and addressee, respectively. A relationship is established between them through a possible world, i.e., a set of possible courses of events. 


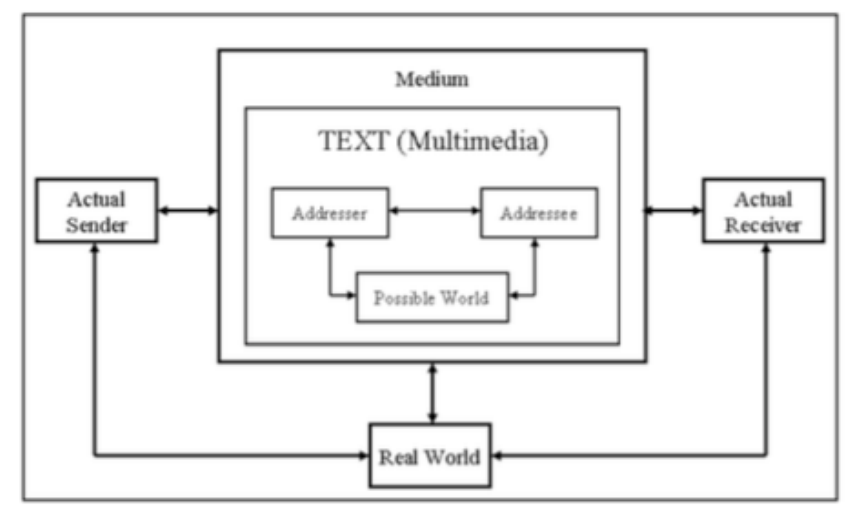

Fig. 1 The communication framework.

The actual sender conceives a document by guessing the receivers' expectations and reactions. Markers of a sender are the graphical and sound logos of a brand, for example; markers of the receiver is the set of features profiling the intended user. Matching the brand identity with the image of it perceived by the users is a fundamental issue for an effective design.

\subsection{The structural scheme}

We represent the multimedia as a text and adopt a semio-narrative model inspired to the structural theory of meaning by A.J. Greimas [18]. The model scheme is sketched in Figure 2.

It comprises four layers: i) axiological; ii) narrative; iii) discourse; and iv) textual layer; the latter - not to be confused with the text as a whole - represents the external manifestation (expression) of a text. The model is conceived to describe texts by going through the layers both in a top-down and a bottom-up fashion.

\subsection{Modelling for analysis and design}

The scheme in Fig.2 represents a conceptual meta-model to be used as a reference for both the analysis and the design of narrative multimedia products. The basic assumption is that the meanings the author intends to communicate (intended meanings) are given a structure organized into multiple, interconnected levels. The meta-model provides the concepts in the structure; the relations among them; the dictionary of terms.

Analysing a given product - an audio-video commercial, for example - involves matching the meta-model with the artefact to single-out, at each level, the constituent elements and relations, as well as guessing how such elements concur to accomplish the communication tasks. The analyst is guided to focus his/her attention of the content issues, and is given a scaffolding to be instantiated with the items of a specific media product. The latter, in turn, provides information 
about how concepts and relations have been actually realized in that product: we can say that the outcome is a model of the multimedia itself.

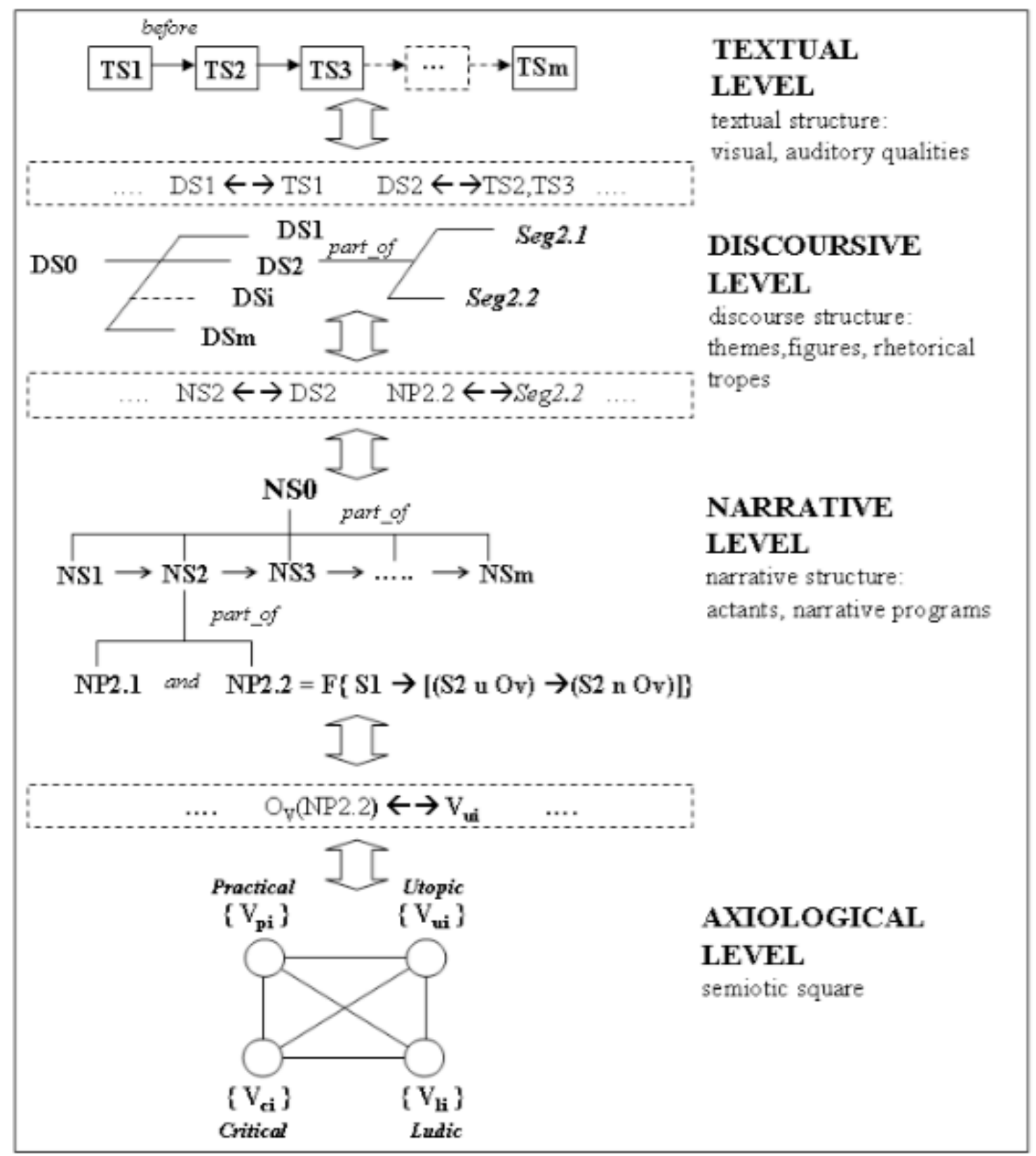

Fig. 2 Graphical scheme of the multimedia structural framework. Following the bottom-up direction: from the axiological to the narrative level, the values $\left\{V_{u i}\right\}$ match the object of value $O_{v}$, which belongs to the Narrative Program NP2.2. The latter is a part of the Narrative Structure NS2. From narrative to discoursive: NS2, possibly split into the segments Seg2.1, Seg2.2 is mapped onto the Discourse (story) Segment DS2, which in turn is mapped onto the textual audiovisual Segments TS2, TS3. 
It should be observed that for a class of products multiple meta-models may be proposed, each one grounded on its own primitive assumptions, with the aim of emphasizing some issues with respect to others. In the same way, no meta-model outperforms the others, the most suitable one being selected according to the final purposes. The framework we propose - as compared with others - offers the opportunity to represent the complex semantic structure of a multimedia according to self-consistent rules, grounded on shared semiotic theories.

We argue that the same meta-model drives the design of novel artefacts, which is strictly connected to its procedural, constructive nature. Concepts and relations are the design variables, i.e., issues to be addressed and given effective solutions by the designer. On general grounds, the design tasks can be regarded as instantiation and constraint satisfaction ones. The meta-model does not provide a well-defined possibily formalized - sequence of tasks to be accomplished by the designer. The latter is left free to refer to it if needed. A few examples can help. It can happen that all levels in the meta-model are to be visited systematically in a bottom-up sense (Fig.2): to establish the deep values to be communicated by the product; the narrative structures; the storytelling solutions; the media assets to express them. As an alternative, the designer may start with a ready-made product, and address analysis and re-design tasks at the different levels without any predefined strategy. Much in the same way, an existing story may be adapted to the values dictated by the brand and given a suitable script, visual and audio tracks.

It follows from our notes that a strict connection holds between analysis and design. For example, whenever an existing multimedia inspires the realization of a new product, a basic task is analysing that product in order to outline its semantic structure and take the appropriate choices. Having at disposal a rich and structured conceptual framework widens the design space - i.e., the set of possible choices and opens the door to creativity and originality.

Ultimately, the framework is a useful reference tool for critical evaluations and ratings of narrative multimedia of a given genre. Reasonable criteria to be adopted are, for example: how the conceptual levels have been realized; how the elements in a level have been put in relation with others; what is the semantic consistency achieved by the product, both on a local and a global scale.

\section{The deep levels}

\subsection{The axiological level}

The deepest level - the axiological one - is that of the values to be transmitted which in advertising are connected to the brand and the product to be commercialized. Such deep values are represented by the semiotic square, exemplified in Figs. 3, 4, 5; the values are organized around basic oppositions, 
assuming that contrasts between values can be the grounding kernels of signification.

The square includes the basic opposition between two conceptual categories, A and B (e.g., life-death). A logical articulation includes four terms: A, not-A, B, not-B, connected by three relations: Contrariety: between A and B; not-A and notB; Contradiction: between A and not-A; B and not-B; Implication or Complementarity: between not-B and A; not-A and $\mathrm{B}$. The scheme is reported in Figure 3.

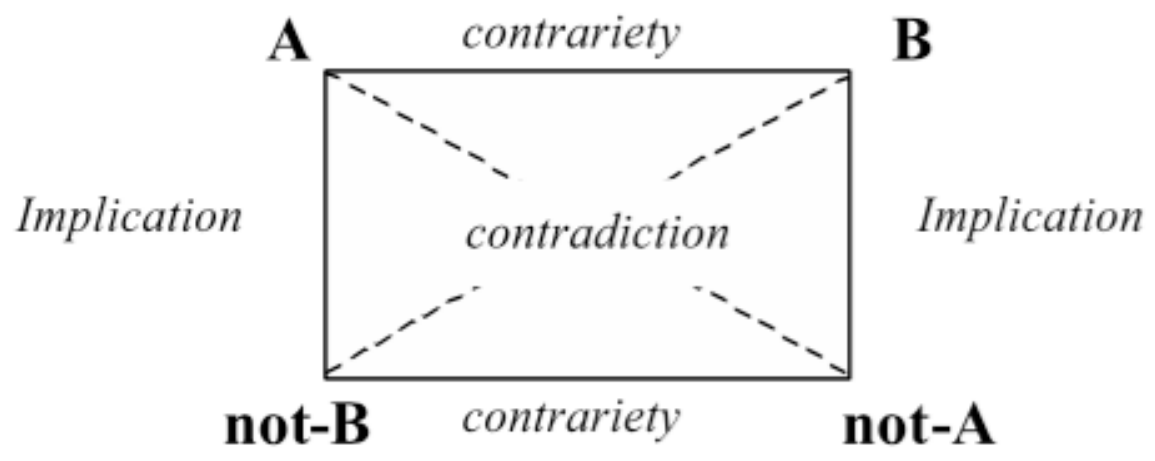

Fig. 3 Logical scheme of the semiotic square.

The scheme allows for movements across the vertices: a path connecting vertices describes a sequence of transformations representing the kernel of possible narratives.

A noteworthy application has been proposed by Floch [14] to single-out the values associated to a consumer product. Four types of exploitations arise from the basic oppositions: practical, critical, ludic, utopic. The first one focuses on effectiveness, usability, reliability; the second, on the economic convenience; the ludic one on the aesthetic pleasure; the utopic one to the individual and social acknowledgments. The scheme has been reported in Figure 4. The square allows the designer to organise a text according to the deep values of a brand, as well as the expectations she/he intends to arouse into the user.

\subsection{The narrative level}

The abstract-logical structure of a narrative is addressed. The level involves the concepts of actant, modality, narrative program. An actant is an abstract entity human, animal, object, avatar - purposively taking part in an action; actants are functional roles that are not yet given a character nor a scene, which will be done at the discourse level. Greimas [18] individuates six kinds of actants: subject, 
object of value $S_{v}, O_{v}$; sender; receiver; helper; opponent. The subject is the one willing - or not - to be joined to an object of value. The sender instigates the action by requesting subject and object to be joined, while the receiver benefits from it. The helper supports the accomplishment, while the opponent hinders it.

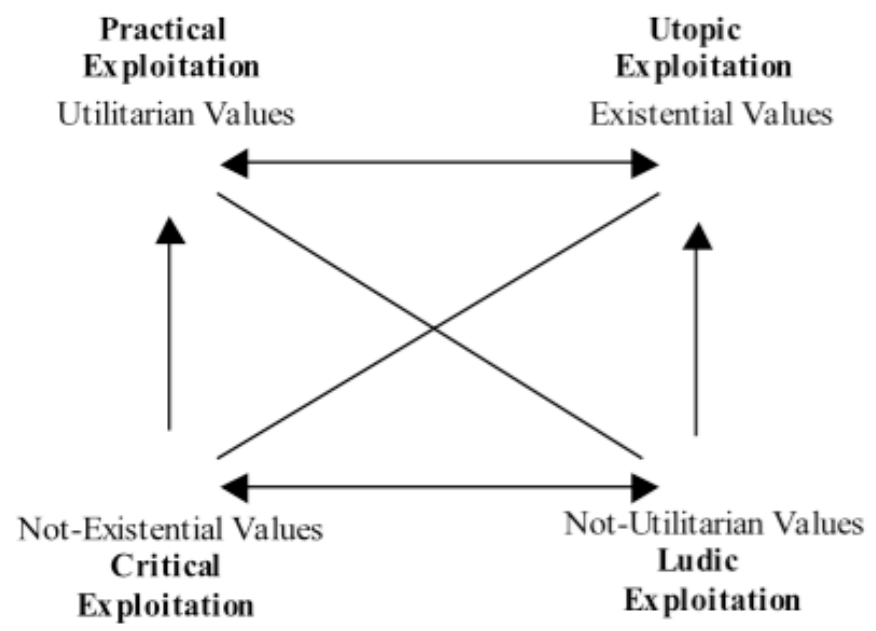

Fig. 4 The semiotic square of a consumer product.

A Narrative Program NP is a building block of a narrative. It is a transition effected by an agent - the subject of doing - affecting a state. The latter is given in terms of subject, object of value; conjunction or disjunction. Formally [22]:

$$
\begin{aligned}
& N P: F\left\{S_{d} \rightarrow\left[\left(S_{s} \cup O_{v}\right) \rightarrow\left(S_{s} \cap O_{v}\right)\right]\right\} \text { conjunctive } \\
& N P: F\left\{S_{d} \rightarrow\left[\left(S_{S} \cap O_{v}\right) \rightarrow\left(S_{S} \cup O_{v}\right)\right]\right\} \text { disjunctive }
\end{aligned}
$$

where $F$ denotes an action; $S_{d}$ the subject of doing; $S_{s}$ the subject of state; $O_{v}$ the value object. The conjunctive $N P$ states that, according to the action $F, S_{d}$ causes $S_{s}$ - originally disjuncted from $O_{v}$ - to be conjuncted with it. An object of value $O_{v}$ may be a physical or an abstract one; a feeling; an objective or a state to be achieved.

Relations between the narrative program and the semiotic square are established by associating the object $O_{v}$ of the former to the values $V_{i j}$ of the latter. In this way, the analyst/designer assigns meaning to an action by directing it to the achievement of an object of value. This captures an essential aspect of sensemaking processes: orienting the course of events toward entities invested with value.

Narrative programs linked by logical relations compose the Narrative Structures 
NSs. Among them, the Canonical Narrative Scheme CNS is a reference structure including: Manipulation: a sender transmits a message, e.g., the mission to reach an object of value; Competence: the receiver attempts to achieve resources to accomplish the mission; Performance: the subject gets the object; Sanction: the sender evaluates the results, and gives a reward or a punishment. Each phase can be recursively decomposed into canonical schemes.

\section{The surface levels}

\subsection{The discourse level}

It is the "storytelling" level, including four classes of constituents: characters, settings, events, processes. Characters are assigned to the actants involved in the narratives; the setting gives narrative a place, time, mise-en-scene. Narrative programs are mapped into a story occurring within a possible world. Logical relations between narrative programs are converted into temporal and causal relations among the story segments. A discoursive structure results in terms of themes and figures: themes provide contents in terms of scripts organizing conceptual entities, while figures act in similar ways evoking sensory perceptions.

Besides characters, the discourse level includes the addresser and addressee. While characters interact within a narrative, addresser and addressee interact through the narrative by playing discoursive roles: narrator, subject of montage, subject of perception. A narrator is charged of producing the narrative, while the others are responsible of montage and points of view of a discourse, respectively.

A relevant issue is the rhetoric one. With the latter we mean whichever solution emphasizing the story events. A distinction holds between rhetorical relations and tropes. The former describe relations among segments of discourse. Adequate formalisms are available, like the Rhetorical Structure Theory (RST) [29] and the Cognitive Coherence Relations (CCR) [28]. Recent studies have applied classical rhetoric rules to images [30]. Adopting rhetorical tropes allows a designer to reinforce the meanings of conceptual items. A further distinction holds between semantic tropes, acting at the content level - metaphors, synecdoche - and syntactic ones like parentheses or ellipses, adopted as style choices at the textual level. In the same way, montage can be used to emphasize events or remove others.

\subsection{The textual level}

It's the concrete manifestation of a storytelling, its expression. It deals with signs, elements that convey the narrative-discoursive content to the user interpretation. The expression uses a representation modality: written or spoken language; image; animation; music; sound effects; video; audiovisual; tactile. It also exhibits 
sensorial qualities and quality relations. We distinguish between tonal qualities static, persistent - and rhythmic ones - dynamic, transient. Examples of visual qualities are color intensity, surface patterns (textures), depth. Auditory qualities are volume, pitch, timbre, tempo, melodic range.

Visual signs are pervasive. Distinguishing is helpful between figurative and plastic signs, as proposed in [19]. The former address images as representing objects because of their resemblance - as icons do - or by virtue of cultural rules, as symbols do. Plastic signs are visual patterns generating meanings - like tension, equilibrium, dynamics, etc. - residing in their pure form, regardless of what they represent. Sensory qualities are inter-related by contrast, affinity or analogy according to the structure relations - e.g., spatial and temporal - among the associated text segments. Qualities of expression are at the base of interpretive activities and impressions affecting the user experience: pragmatic, like usability; hedonic, like emotion and aesthetic pleasure.

Decisions taken at the textual level are related to those at the discoursive and narrative ones, and the reverse: transitions from narrative to discoursive structures are accompanied by rhetorical choices; characters in a story/discourse have to be expressed by suitable audio-visual shots.

\section{A case study}

\subsection{Steps of the analysis}

We analysed and compared four narrative clips of the Tresor perfume by Lancôme. All clips tell of a dating between a woman and a man. The woman is interpreted by glamorous actresses called "the Muses" by Lancôme itself. They are Isabella Rossellini [43]; Ines Sastre [44]; Kate Winslet [45]; Penelope Cruz [46]; we denote each clip by their initials IR, IS, KW, PC.

For each audio-visual sequence we have carried out an analysis according to the meta-model we proposed in Sections 3, 4, by crossing the model levels in a topdown fashion (see fig.2).

The results of each clip have been mutually compared in order to gain an insight into the communication strategy of the brand.

\subsection{Results}

\section{Textual analysis}

Visual track. A technical decoupage was performed, and the track segmented into shots and scenes. For each shot the initial and final frames were identified; then, the overall duration of shots and scenes. 
Table 1 Textual analysis of the IR clip.

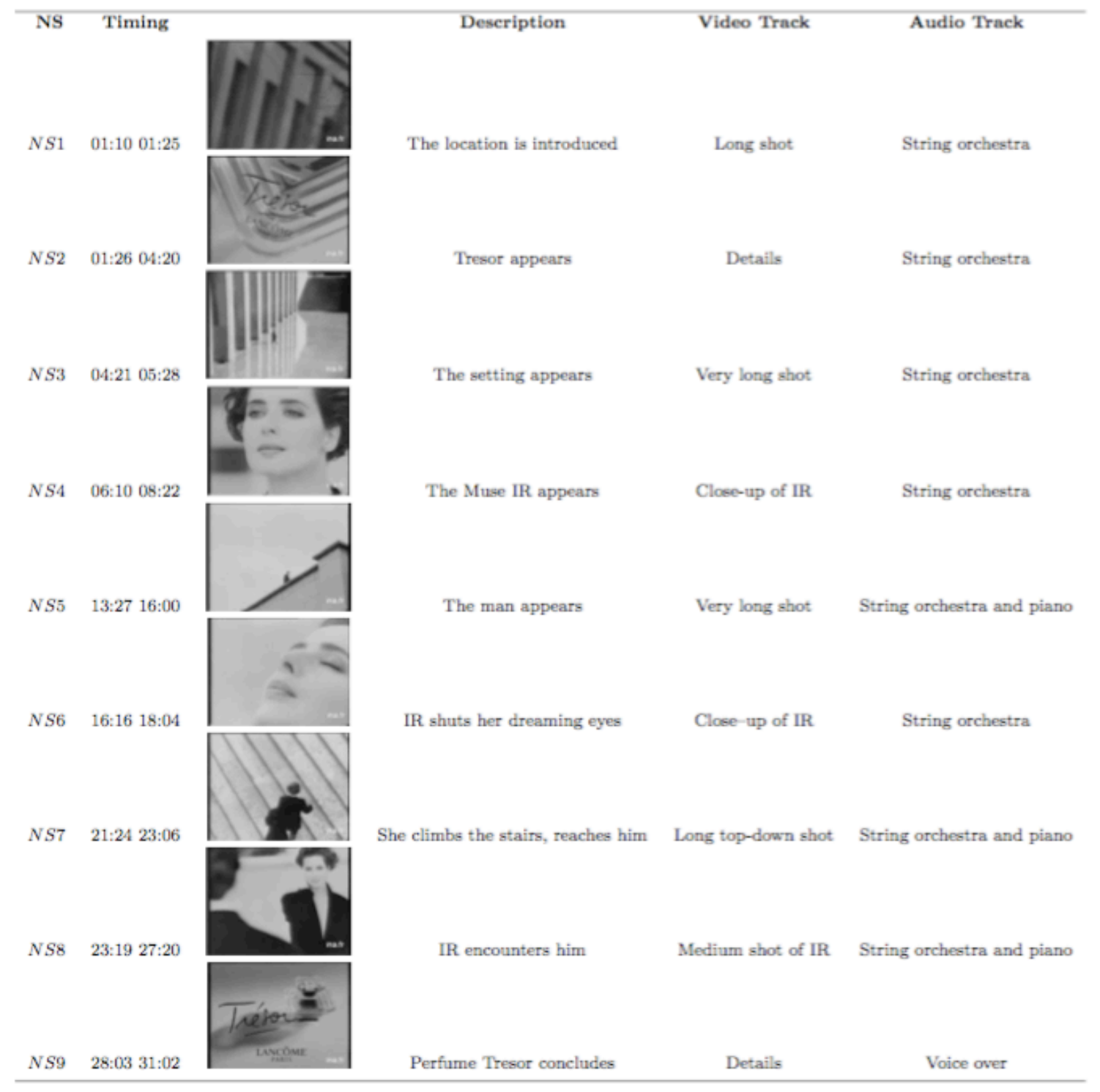

Plastic issues dominate in IR, IS. In IR, vertical and oblique straight lines characterising the architectural setting - contrast with the rounded forms of face and body of the Muse, and together create a rhyme with the shape of the bottle of perfume, thus establishing a connection between the story and the brand/product. Dominant colours are rose, metaphorically reminding the essence of the scent Tresor; desaturated blue, suggesting elegance, serenity and safeness; gold-red used for expressing the background mood. Again, gold-red color rhymes with the bottle of perfume remind preciousness and rarity. Achromatic, de-saturated colors; low contrasts; shades of grey, may be associated with abstraction, fantasy, dream which is consistent with the conceptual use of figurative images [24]. From a topological point of view, the opposition between top - typically meaning the space of ideals and promises - and bottom, space of the real and the product, is 
represented in the IR clip by the relative positions of characters: the Muse at the bottom and the man waiting for her at the top. Consequently, the IR Muse moving towards the man is interpreted as approaching the ideal, which is consistent with the object of value played by the man at the narrative level. The positions of Muse and man appear reversed in the PC clip, while in IS and KW no opposition is observed, signifying a balanced relationship between the two characters. By comparing the IR and PC clips, one argues that some subordination of the Muse to the man is signified by IR, while the reverse happens in PC: the observation holds both at the textual and the narrative level, consistently.

Close-up and very close-up shots occur more frequently in IR, PC, denoting a friendly intimate relation. Detail shots appear in IS. Long and medium-long shots represent social or impersonal relations: their frequency is roughly the same in all clips. Changes of shots are iconified: cuts are used within KW, PC; dissolves in IR, IS. Soft focus (flou) is used mainly in IR. The cutting rate is remarkably higher in the KW clip, to emphasize the rising emotional tension. We report in Table 1 a part of the textual analysis applied to the IR clip. Shots are represented by key frames.

Audio track. The analysis of auditory qualities (Section 4.2) has been accomplished by sound experts. They were asked to describe sound objects spoken words, sound effects - in terms of impressions induced into a listener. A comprehensive description of the relationships among audio features and emotions can be found in [17]. There followed a quantitative spectro- morphological analysis in the time and frequency domains. Sonograms of each track were computed. A detailed account has been reported in ref. [42].

The rhythm is generally slow, apart from KW which is given a faster one in accordance with the story enacted therein. The sound medium adopts different arrangements of the same background motive. A voice over introduces the product in all clips. String orchestra and piano play in IR; the piano theme suggests a thoughtless atmosphere. In IR a string orchestra plays; tightly bound and leaning notes suggest solemnity and a feeling of safeness. In KW a string orchestra cues to a fairy atmosphere. In PC: string orchestra, piano and guitar, the latter perhaps in relation with the spanish citizenship of Cruz.

\section{Discourse analysis}

The clips share the theme of a dating: a woman, a man, a place, a bunch of flowers. Settings are different: not easily identifiable in IR; the Doge's Palace in Venice for IS; roads and a bridge in Paris for KW; roads and an apartment in Paris for PC. The addresser is represented by the brand Lancôme and the product Tresor appearing here and there during the clips. The addressee is a woman mirroring herself into the Muse. Rhetoric solutions are mainly metaphors. The mechanism is 
called "transference" [7]: the viewer is brought to transfer the qualities signified by the actresses - beauty, elegance, glamour - to the perfume, thus creating a new sign with the meaning: "Tresor is indeed beauty and charme".

\section{Narrative analysis}

All clips share a unique, basic narrative program NP. With the notations adopted in Section 3.2 NP reads: the subject of doing $S_{d}$ does the action $F$ in order that the subject of state $S_{s}$ is joined with the object of value $O_{v}$.

The four clips differ by the way roles are assigned. In IR, IS the woman moves to meet the man waiting for her; in $\mathrm{KW}$, both move to meet each other, which implies that the narrative program splits into two parallel ones. In any case, the purpose of the action is meeting the partner, i.e., the object of value. The perfume Tresor itself is an actant playing the role of a helper. In the KW clip the road traffic in Paris acts as an opponent to the encounter.

Pieces of the Canonical Narrative Scheme (CNS, Sec. 3.2) can be recognised in the clips as well. Competence: in KW, PC the subject must be able to move into the traffic and purchase a bunch of flowers; Performance: is there in all clips; KW and PC request to overcome the city traffic, i.e., the opponent; Sanction: in KW is the final embrace. Manipulation is not present explicitly.

\section{Axiological analysis and comparisons}

Our axiological analysis reveals that the four clips are built on top of two basic oppositions: reality/dream; non-dream/non-reality, which compose the semiotic square 5. The clips can be grouped into two homogeneous pairs. The IR and KW ones are associated to the concepts dream/non-reality. In particular, IR is characterized by a rarefied atmosphere of dream: locations are not well defined; the background is blurred. The aim is focusing the viewer's attention on a woman and her qualities rather than a true narrative. On the other hand, KW shows the dating under a passional, emotional perspective which is far from the everyday life. The second pair, PC and IS, is associated to reality/non-dream. Both clips represent the dating in a more realistic and situated fashion.

Therefore, it is interesting to observe that the semiotic square was not used as a kernel of meanings of a single clip, but as a tool to conceive a portfolio of several related clips, as depicted in Figure 5. The pairings we propose have been confirmed by analysing the sound tracks independently. It is also noteworthy that the advertising campaigns by Lancôme from 1990 to 2010 alternated clips from the first and the second pairings.

The deep values associated to the brand are to be distinguished by those associated 
to the product. The former should be constant in time to foster credibility and trust; the latter may change over time to better fit to the social changes occurring within the target customers. In our case, the brand Lancôme emphasizes quality and expertise in the domain of beauty: they are invariably reflected onto the stories in terms of "art of living" with elegance and refinement. On the other hand, the product Tresor - tied to femininity - is associated to the different actresses playing the role of Muses.

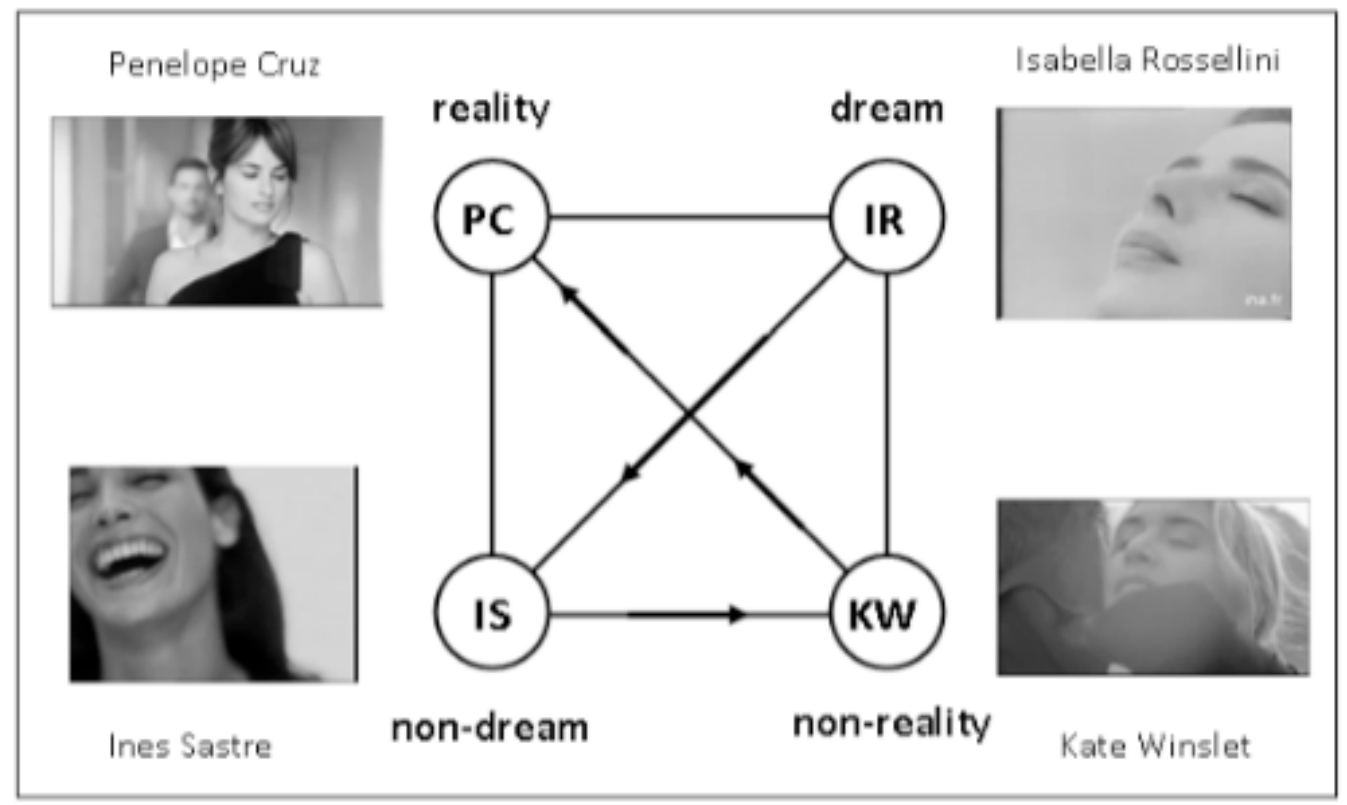

Fig. 5 The semiotic square and the brand Lancôme.

\section{Conclusions}

We have proposed a meta-model of multimedia. Practical issues have been explored by analyzing a set of commercials. Our work confirms that the framework offers semantically rich solutions towards the analysis, comparison, an- notation of multimedia products, as well as useful suggestions for their design. We summarize the main contributions of the paper.

\section{A reference model}

The framework is inspired to semiotic theories. Accordingly, the semantics of a text is given a structure by means of constructive processes. There results a clearcut organization of concepts, relations and mappings to be used as a meta-model. The meanings result from mappings at different abstraction levels, that can be afforded in top-down and bottom-up directions. Four levels of signification support the analysts/users. Two deep levels - value, and narrative-based, 
respectively - underly the story and presentation ones, thereby ensuring multiple paths connecting contents and expression.

The original approach by Greimas - proposed in the domain of structural semiotics - has been interpreted and adapted to the context of multimedia products. Substantial modifications have been applied, especially at the textual level, by adopting concepts of visual and social semiotics (refs. [19, 24]).

The global consistency of the framework is one of its main advantages. On one hand, analysts may investigate a multimedia text starting by its visual and audio tracks; by individuating storytelling, rhetorical solutions; by reconstructing the narrative scaffolding; by capturing the underlying ethical and pragmatic values. On the other hand, designers may browse the model toolkit to assemble chunks of narratives into story segments and express them in an effective style.

\section{Explorative analysis}

We have afforded the analysis of four commercials by Lancôme, as a case study to explore the potentialities of our framework. The results demonstrate that it provides compelling, semantically rich descriptions. Our analysis has revealed some unexpected features of the commercial clips, which are usually hidden behind the appearance of the media objects.

The framework shows up to be effective in communicating deep values: the wellknown power of narratives is given an explicit, structured, consistent picture in terms of a toolkit made available to designers and users. It works as a reference model, i.e., it contains no prescriptive rules, nor formalisms to be strictly committed to. On the contrary, room is given to creative solutions as expected in high quality multimedia products.

\section{Limitations and beyond}

The conceptual framework we have proposed is complex. Is it worthwhile doing such an effort? As long as designers of multimedia achieve fair results by operating empirically, why sticking to complex schemes?

We believe that a number of applications of multimedia demand an effective communication of messages: for example, whenever the trust and the involvement of users are to be achieved, like in marketing and education. The meta-model helps both designers and users to be aware of the messages to be shared, which supports the transparency of campaigns with commercial, educational, ethical purposes. The quality assessment of multimedia products is enabled as well, by referring to the mutual consistency of values; narrations; storytelling and media issues. 
Another objective under reach is formalizing the semantics of the framework in the computational form of an ontology. In addition, the semantic indexing of multimedia is under reach. Our work is progressing along these lines.

\section{References}

1. Baley, B., Konstan, J., Carlis, J., 2001. Supporting multimedia designers: towards more effective design tools. In: Proc. Modeling Multimedia Information and Systems (MMM 2001), pp. 267-286.

2. Bardzell, J., 2009. Interaction criticism and aesthetics. In: Proc. CHI2009, Boston, MA, USA, pp. 2357-2366.

3. Bateman, J.A., 2007. Towards a grande paradigmatique of film: Christian Metz reloaded. Semiotica, 167, 1/4, pp. 13-64.

4. Bianchi, C., 2011. Semiotic approaches to advertising texts and strategies: Narrative, passion, marketing. Semiotica 183, 1/4, pp. 243-271.

5. Bolchini, D., Chatterji, R., Speroni, M., 2009. Developing heuristics for the semiotics inspection of websites, In: Proc. 27th ACM Int. Conf. on Design of Communication, pp. 67$72,2009$.

6. Bouvier, G., Machin, D., 2013. How advertisers use sound and music to communicate ideas, attitudes and identities: A multimodal critical discourse approach. In: B.Pennock Spek \& M.M.Del Saz Rubio (Eds.), The Multimodal Analysis of Television Advertising, University of Valencia Press, Valencia, SP.

7. Chandler, D., 2002. Semiotics: The Basics. Routledge, London and New York.

8. Cockton, G., 2006. Designing worth is worth designing. Proc. NordiCHI Conference, ACM Press, pp. 165-174.

9. Colombo, C., Del Bimbo, A., Pala, P., 2001. Retrieval of commercials by semantic content: The semiotic perspective. Multimedia Tools and Applications, Vol.13, Kluwer Academic Publishers, pp. 93-118.

10. Davis, M., 1994. Knowledge representation for video. In: Proc. 12th National Conf. on Artificial Intelligence (AAAI-94), Seattle, Washington, AAAI Press, pp. 120-127.

11. De Saussure, F., 1922. Cours de Linguistique Generale. (In French). Payot, Paris.

12. Desmet, P.M.A., Pohlmeyer, A.E., 2013. Positive Design: an introduction to design for subjective well-being. International Journal of Design, Vol.7, 3, pp. 5-19.

13. Eugeni, R., 2011. Media experiences and practices of analysis. For a critical pragmatics of media. In: Int. Workshop Practicing Theory, Univ. Amsterdam, NL, 2011.

14. Floch, J.M., 2001. Semiotics, Marketing and Communication: Beneath the Signs, the 
Strategies. Palgrave, Hampshire.

15. Fogg, B., 2003. Persuasive Technology: Using Computers to Change What We Think and Do. Morgan Kaufmann, San Francisco, CA, USA.

16. Friedman, B., Kahn, P.H., Borning, A., 2006. Value sensitive design and Information systems, In: P.Zhang, D.Galletta (Eds.), Human-Computer Interaction and Management Information Systems: Foundations. Sharpe Inc., New York, NY, pp. 348-372.

17. Gabrielson, A., Lindstrom, E., 2001. The influence of musical structure on emotional expression. In: P.Juslin, J.Sloboda (Eds.), Music and Emotion Theory and Research. Oxford University Press, New York, NY, pp. 223-248.

18. Greimas, A.J., Courtes, J., 1982. Semiotics and Language. An Analytical Dictionary. Indiana University Press, Bloomington, IN, USA.

19. Greimas, A. J., 1984. Semiotique figurative et semiotique plastique. In: Actes semiotiques. Documents, N.60 (in French).

20. Harrison, C., 2003. Visual social semiotics: understanding how still images make mean ing. Technical Communication, Vol.50, 1, pp. 46-60.

21. Hassenzahl, M., 2010. Experience Design: Technology for all the right reasons. San Rafael, CA, USA, Morgan \& Claypool.

22. Hebert, L., 2006. Tools for Text and Image Analysis: An Introduction to Applied Semiotics. URL: http://www.revue-texto.net/Parutions/Livres-E/Hebert AS/Hebert Tools.html

23. Islam, M.N., Bouwman, H., 2016. Towards user-intuitive web interface sign design and evaluation, International Journal of Human-Computer Studies, Vol.86, C, Academic Press, pp. 121-137.

24. Kress, G., van Leeuwen, T., 2006. Reading Images: The Grammar of Visual Design. Routledge, London.

25. Kujala, S., Vaananen-Vainio-Mattila, K., 2009. Value of information systems and products: understanding the users' perspective and values. Journal of Information Technology Theory and Application, JITTA, Vol.9, 4, pp. 23-39.

26. Lauer, C., 2009. Contending with terms: 'Multimodal' and 'Multimedia' in the Academic and Public Spheres. Computers and Compositions, Vol.26, pp. 225-239.

27. Lombardo, V., Damiano, R., 2010. Narrative annotation and editing of video. In: Proc. ICIDS'10, Third Joint Conference on Interactive Digital Storytelling, pp. 62-73.

28. Mancini, C., Buckingham Shum, S.J., 2001. Cognitive coherence relations and hypertext: from cinematic patterns to scholarly discourse. In: Proc. Hypertext 2001.

29. Mann, W.C., Thompson, S., 1988. Rhetorical Structure Theory: toward a functional theory of text organization. Text, Vol.8, 3, pp. 243-281.

30. McQuarrie, E.F., Mick, D.G., 1999. Visual rhetoric in advertising: Text-interpretive, 
experimental, and reader-response analyses. Journal of Consumer Research, Vol. 26.1, pp. $37-54$.

31. Montero, S., Diaz, P., Aedo, I., 2003. A Framework for the analysis and comparison of hypermedia design methods. In: Proc. Appl. Informatics 2003, Innsbruck, A, pp. 1053-1058.

32. Nadin, M., 1988. Interface design: a semiotic paradigm. Semiotica, 69, pp. 269-302.

33. O’Halloran, K.L., 2011. Multimodal Discourse Analysis. In: K.Hyland, B.Paltridge (Eds.), Companion to Discourse. London and New York: Continuum, pp. 120-137.

34. Purchase, H.C., Naumann,D., 2001. A semiotic model of multimedia. Theory and evaluation. In: Design and Management of Multimedia Information Systems: Opportunities and Challenges, Idea Group Publishing, pp. 1-24.

35. Rogers, Y., 2004. New theoretical approaches for human-computer interaction. Annual Review of Information Science and Technology, Vol.13, 1, pp. 87-143.

36. Scharfe, H., 2007. Grand principles of narratology. In: I.Bas, C.Freeman (Eds.), Challenging the Boundaries, Rodopi, Amsterdam, NL, pp. 95-110.

37. Sieckenius de Souza, C., 2001. Semiotic Approaches to User Interface Design, Editorial, Knowledge-Based Systems, Vol.14, 8, Elsevier, pp. 415-418.

38. Sieckenius de Souza, C., 2004. The Semiotic Engineering of Human-Computer Interaction. The MIT Press, Cambridge, MA, USA.

39. Sieckenius de Souza, C., 2013.Viewpoint: Semiotic perspectives on interactive languages for life on the screen, Journal of Visual Languages and Computing, Vol.24, 3, pp. 218- 221.

40. Snoek, C.G.M., Worring, M., 2005. Multimodal video indexing: a review of the state- ofthe-art. Multimedia Tools and Applications, Vol.25, pp. 5-35.

41. Toppano, E., Roberto, V., 2009. Semiotic design and analysis of hypermedia. In: Proc. 20th ACM Conference on Hypertext and Hypermedia, HT2009, Turin, I, pp. 367-368.

42. Toppano, E., Toppano, A., 2014. The role of sound in brand communication. In: Proc. of the Int. Conference on e-Commerce, Lisbon, P. Computer Science and Information Systems Series, IADIS Press, pp. 167-174.

43. Tresor by Lancôme, Isabella Rossellini, 1990.

URL:http://www.youtube.com/watch?v=HGfTmAucZb8

44. Tresor by Lancôme, Ines Sastre, 2007.

URL:http:/www.youtube.com/watch?v=tnkoEXlENFY

45. Tresor by Lancôme, Kate Winslet, 2009. URL:http://www.youtube.com/watch?v=skIjtbljMQ

46. Tresor by Lancôme, Penelope Cruz, 2010. URL:http://www.youtube.com/watch? $\mathrm{v}=\mathrm{eBs}$ $8 \mathrm{kfOCY}$ 
47. Tromp, N., Hekkert, P., Verbeek, P.P., 2011. Design for socially responsible behavior: A classification of influence based on intended user experience. Design Issues, Vol.27, 3, pp. 3-19.

48. Tseng, C., 2013. Analysing characters' interactions in filmic texts: a functional semiotic approach. Social Semiotics, 23, 5, pp. 587-605.

49. Verbeek, P.P., 2006. Materializing morality: design ethics and technological mediation. Science, Technology \& Human Values, Vol.31, 3, pp. 361-380.

50. Wingstedt, J., Brandstrom, S., Berg, J., 2010. Narrative music, visuals and meaning in Film. Visual Communication, Vol.9, 2, pp. 193-210.

51. Wouken, A., Carr, L., Wills, G., Hall, W., 2002. Rethinking web design models: requirements for addressing the content. Tech. Rep. N.ECSTR-IAM03-002, Univ. Southampton, UK.

52. Wright, P., Wallace, J., McCarthy, J., 2008. Aesthetics and experience-centered design. ACM Trans. on Computer-Human Interaction, Vol.15, 4, Art.18. 